\title{
Análise estatística da movimentação no porto de Presidente Epitácio, SP
}

\author{
Luís Roberto Almeida Gabriel Filho ${ }^{1}$, Camila Pires Cremasco ${ }^{2}$, Rodrigo de Oliveira Souza ${ }^{3}$
}

${ }^{1}$ Professor Doutor do curso de Administração (CET, UNESP, Presidente Prudente) e do curso de Pós-Graduação em Agronomia/Irrigação e Drenagem (FCA, UNESP, Presidente Prudente); ${ }^{2}$ Professor Doutor do curso de Tecnologia no Agronegócio (FATEC, Presidente Prudente); ${ }^{3}$ Mestrando em Matemática Aplicada e Computacional (FCT, UNESP, Presidente Prudente).

\section{Resumo}

Os sistemas de transporte podem contribuir para o desenvolvimento do país, pois impulsionam o crescimento do PIB. No Brasil o transporte hidroviário é pouco utilizado para a movimentação de produtos no mercado interno, se destacando somente para escoamento de mercadorias para os mercados externos. A modalidade de transporte hidroviário é indicada para movimentação de cargas a granéis, além de possuir a capacidade de se movimentar grandes quantidades. O Brasil possui uma grande quantidade de portos e terminais, mais somente alguns são utilizados durante o ano. O porto de Presidente Epitácio já foi muito utilizado como rota de transporte de produtos agrícolas, no entanto, apresentou um declínio na sua utilização nos últimos anos, mesmo se mostrando uma ótima opção. A pesquisa teve como proposta analisar as vantagens da modalidade hidroviária, assim como a utilização do terminal portuário de Presidente Epitácio, identificando os gargalos que ocasionam o atual baixo fluxo de cargas. A análise de campo concluiu que a movimentação de carga é pequena, se comparada com sua capacidade de movimentação. Um dos motivos da sua baixa participação no transporte nacional ocorre pela preferência do modal rodoviário, e pelo fato da ferrovia estar paralisada, mais que provavelmente ainda 2009 será reativada.

Palavras-chave: transporte hidroviário, frete, fluxo de cargas.

\section{Statistical analysis of the port movement on Presidente Epitácio, SP}

\begin{abstract}
Transport systems can contribute to the development of the country, for driving the growth of GDP. In Brazil, the water transport is little used for the movement of products in the market, standing out only for disposal of goods to foreign markets. The mode of water transport is suitable for handling the bulk, it has the ability to move large quantities. Brazil has a lot of ports and terminals, plus only a few are used during the year, the port of Epitácio has been widely used as a transportation route for agricultural products, however, showed a decline in its use in recent years, even if showing a great option. The study was proposed to analyze the benefits of the waterway mode, and the use of Epitácio port terminal, identifying the bottlenecks that cause the low current flow of cargo. Field analysis concluded that the handling is small compared with its ability to drive. One of the reasons for low participation in national transport is the preference of the road system, and because of the railroad being paralyzed, most likely later this year will be reactivated.
\end{abstract}

Keywords: water transportation, freight, load flow. 


\section{Introdução}

O Brasil é um grande produtor agrícola, por possuir disponibilidade de terras agricultáveis, água em abundância, condições de clima favoráveis, domínio da tecnologia de agricultura tropical e uma agroindústria avançada, podendo chegar a ser a principal potência agrícola mundial.

Um dos desafios para que a produção agrícola continue a crescer e se desenvolver, é a solução dos problemas relacionados à infraestrutura de transporte.

Os sistemas de transporte podem contribuir para o desenvolvimento do país, pois impulsionam o crescimento do Produto Interno Bruto (PIB), ao movimentar as riquezas nacionais ligando áreas produtoras a mercados consumidores.

A matriz de transporte mais utilizada no país é a rodoviária, mesmo condicionada a uma serie de limitações. Dentre tais limitações, pode se destacar o elevado custo de frete, quando comparado com as modalidades ferroviário e hidroviário.

Conforme Barat (2007), o frete corresponde a cerca de $10 \%$ a $15 \%$ do preço final da mercadoria, variando de acordo com o tipo de carga e com o tempo da viagem. Como alguns produtos agrícolas apresentam baixo valor agregado, o preço do frete se torna consideravelmente alto no preço final do produto.

As modalidades hidroviária e ferroviária são as mais indicadas para o escoamento de produtos agrícolas, no entanto são pouco utilizadas. A infra-estrutura férrea e portuária encontra-se, no geral, em péssimo estado.

A modalidade de transporte hidroviário é indicada para movimentação de cargas a granéis, além de possuir a capacidade de se movimentar grandes quantidades, sendo economicamente desejável que este modal seja utilizado entre origem e destino. Para isto faz-se imprescindível a utilização dos terminais portuários, porém sua utilização no Brasil é muita restrita, ou seja, há vários portos e terminais privados, porém somente alguns específicos são utilizados.

O terminal portuário de Presidente Epitácio já foi considerado o segundo maior do país em 1974, entretanto, atualmente é muito pouco utilizado, apesar de suas vantagens.

O transporte é fundamental nas cadeias produtivas, sendo ele o elo responsável por ligar toda cadeia de produção, possibilitando interação entre estados produtores e cidades consumidoras. Entretanto, no Brasil há uma predominância do modal rodoviário mesmo não sendo indicado.

Desta forma a presente pesquisa buscou estudar a modalidade hidroviária por ser mais indicada na movimentação agrícola, no entanto pouca utilizada para essa movimentação no mercado interno, se destacando somente para escoamento de mercadorias para os mercados externos, incluindo-se aí o terminal portuário de Presidente Epitácio.

Apesar de o terminal ter apresentado grande participação no desenvolvimento da região e uma significativa parcela nacional, no entanto, se encontra paralisado, mesmo depois da sua recolocação e das melhorias de infra estrutura.

A pesquisa propôs verificar, estaticamente, a movimentação que ocorreu no porto, e averiguar os motivos do declínio de sua participação na movimentação de cargas agrícola.

\section{Modalidade hidroviária}

O transporte hidroviário é pouco utilizado para escoamento de cargas no interior do país. A sua maior utilização ocorre em navegações de longo curso. Conforme a CNT (2006), o Brasil utiliza, durante o ano, apenas $10.000 \mathrm{~km}$ das vias navegáveis para o transporte de cargas, mas a 
extensão da rede hidroviária pode ultrapassar $40.000 \mathrm{~km}$

Segundo Felipe Junior (2008), o transporte fluvial em comparação ao ferroviário e, sobretudo, ao rodoviário, apresenta as seguintes especificidades e vantagens do ponto de vista econômico: o baixo custo do frete e a grande capacidade de escoamento de cargas, do ponto de vista natural, um sistema que respeita em parte o traçado original dos rios e é menos agressor ao meio ambiente, do estrutural, necessita da intermodalidade para melhor funcionar, e em relação do risco, se caracteriza pela baixa ocorrência de acidente.

Estima-se que o custo de transporte por quilômetro em uma hidrovia seja duas vezes menor que o da ferrovia e cinco vezes mais baixo que a rodovia (CNT, 2006).

Dentre as vantagens do transporte hidroviário, é possível destacar a elevada capacidade de transporte, o frete mais barato que nos modais rodoviário e ferroviário, e o fato de possibilitar o uso da multimodalidade. Por outro lado, entre as desvantagens deste tipo de transporte figuram a baixa velocidade (em média $10 \mathrm{Km} / \mathrm{h}$ ), as rotas fixas e a quantidade de rios navegáveis baixa.

De acordo com Bravin (2001) são transportáveis por uma via navegável produtos que apresentam as seguintes características:

- Baixo custo por unidade de peso;

- Volumes apreciáveis;

- Grandes distâncias de transporte;

- Adaptação em termos de custos às baixas velocidades;

- Grande volume por unidade de peso;

- Comercialização estável.

Além do ponto de vista econômico (baixo custo do frete), do ponto de vista natural é um sistema que respeita em parte o traçado original dos rios, sendo menos agressor ao meio ambiente. É o que possui menor emissão de poluentes, em torno de vinte vezes inferior ao rodoviário e quatro vezes menor que o ferroviário, podendo ser considerado uma matriz de transporte econômico-ambiental.

Podemos destacar como vantagens ambientais da modalidade hidroviária, comparada com as outras modalidades, sobretudo ao rodoviário:

- Menor consumo de combustível;

- Menor emissão de poluentes;

- Menores congestionamentos de tráfego;

- Baixa ocorrência de acidentes com a carga;

- Baixa quantidade de Impactos ambientais.

Entre suas vantagens se destaca também a sua grande capacidade de escoamento, um caminhão carrega cerca de 150 vezes menos soja do que uma composição ferroviária e cerca de 600 vezes menos do que um comboio de barcaças numa grande hidrovia como a do TietêParaná, comparando com o ponto de vista do impacto ambiental e emissões de poluentes na atmosfera.

\section{Material e métodos}

O estudo foi delineado como estudo de caso, devido este tipo de pesquisa permitir se aproximar da realidade.

Os dados foram obtidos através de constante estudo bibliográfico e de uma visita técnica com aplicação de entrevista, que ocorreu em fevereiro de 2009 no porto de Presidente Epitácio, com o objetivo de verificar a sua atual situação.

A entrevista realizada no porto foi concedida pelo Diretor-Geral da ATEPPE, sendo que os dados foram analisados através de 
estatística descritiva, com discussão de Boxplot avaliando as médias, moda, mediana e o desvio padrão dos dados.

Os gráficos Boxplot e de barras foram desenvolvidos pelo software estatístico Minitab 15 , visto que sua interface gráfica permitiu obter bons resultados visuais. $\mathrm{O}$ gráfico de movimentação na hidrovia Paraná foi realizado com a utilização do software estatístico SPSS 10.0, que permite personalizar o gráfico de maneira mais prática.

\section{Resultados e discussão}

De acordo com a Administração do Terminal Portuário de Presidente Epitácio (ATEPPE, 2009), a construção do terminal portuário de Presidente Epitácio ocorreu na década dos anos 60, incentivada pela movimentação de cargas de gado, madeiras, mate e cereais, proveniente do Mato Grosso do Sul e demais estados vizinhos. Em 1974, Presidente Epitácio era o segundo, maior Porto Fluvial do país, perdendo apenas para o Corumbá (MS).

Com a construção da Usina Hidrelétrica "Sérgio Motta", e com a formação do lago, o porto teve que ser desativado em 1998, para uma nova substituição posteriormente realizada pela CESP (Companhia Energética do Estado de São Paulo).

O terminal é administrado pela Administração do Terminal Portuário de Presidente Epitácio (ATEPPE), sendo a mesma uma autarquia municipal criada em 28 de março de 2003, através da lei 027/2003. O transporte hidroviário é responsabilidade da SARTCO que pertence ao grupo ADM, e armazenagem do Centro Sul.

O porto não está totalmente equipado devido a pouca movimentação, possui apenas um elevador para 1400 toneladas/dia, mas conforme - Diretor-Geral da ATEPPE de Presidente
Epitácio tem condições de ser equipado, e atender a todos os tipos cargas e embarcações.

Em junho de 2008 houve sua reinauguração com uma carga de origem Paraguai, sendo dois comboios de 4.500 (toneladas) cada, obtendo um total de aproximadamente 9.000 toneladas.

As instalações da área interna e externa possuem respectivamente capacidade para noventa e cinqüenta vagões, possui um escritório que servirá como base da receita federal, possui iluminação de acesso e de pátio permitindo que ocorram operações vinte e quatro horas por dia (Figura 1).

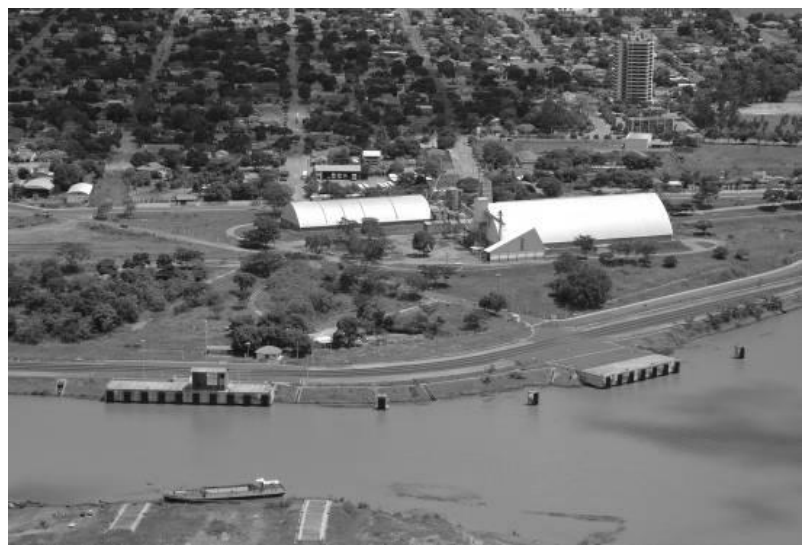

Figura 1. Vista panorâmica do Terminal portuário de Presidente Epitácio.

O porto possui acessos pelas modalidades rodoviária, ferroviária, hidroviária, que podem ser usadas de maneira integrada.

$\mathrm{O}$ acesso rodoviário ocorre pelas SP270/BR-267 principais rodovias que ligam 0 estado de São Paulo com o Mato Grosso do Sul, além de possuir anel viário que facilita 0 acesso desta modalidade ao porto sem a necessidade de ser passar por dentro do município. O ferroviário pela unidade regional de Presidente Prudente, hoje administrado pela concessionária América Latina Logística (ALL), o acesso hidroviário ocorre pelo reservatório Sérgio Motta do Rio Paraná, 
sendo de responsabilidade a Administração da Hidrovia Paraná (AHRANA).

O cais de Presidente Epitácio se mostra uma ótima opção para embarque e desembarque de produtos agrícolas devido a sua localização. Possuindo uma área de influência que não é delimitada, podendo ser movimentadas cargas dos tipos líquido, sólido, granéis, de todas as cidades nacionais e internacionais onde há abrangência da hidrovia Paraná.

A Hidrovia do Rio Paraná apresenta as seguintes dimensões físicas:

- Extensão da Hidrovia é de 1.020,00 $\mathrm{km}$;

- Extensão do canal em corrente livre 245,00 Km;

- Extensão do canal em Reservatórios $785,00 \mathrm{Km}$;

- Largura do Canal de Navegação 45,20 a $300 \mathrm{~m}$.

A Hidrovia movimentou 5.037.862 toneladas de janeiro a dezembro de 2008 , sendo sua capacidade máxima de movimentação de cargas de 6.500.000 t/ano e capacidade potencial de movimentação de cargas, com obras de melhorias, de 13.100.000 t/ano. Os principais produtos transportados na hidrovia são os grãos e derivados, seguidos por areia e cascalho para construção civil, calcário e fertilizante, mas também madeira, carvão e carne. Neste ano, o total transportado foi 2.981 .587 de toneladas de janeiro a julho conforme os dados da AHRANA (2009).
Observando as operações que ocorreram até julho de 2009 na hidrovia, pode-se perceber que quase $77 \%$ da movimentação foi de granéis e $23 \%$ de outros tipos de cargas, o que está ilustrado na Figura 2.

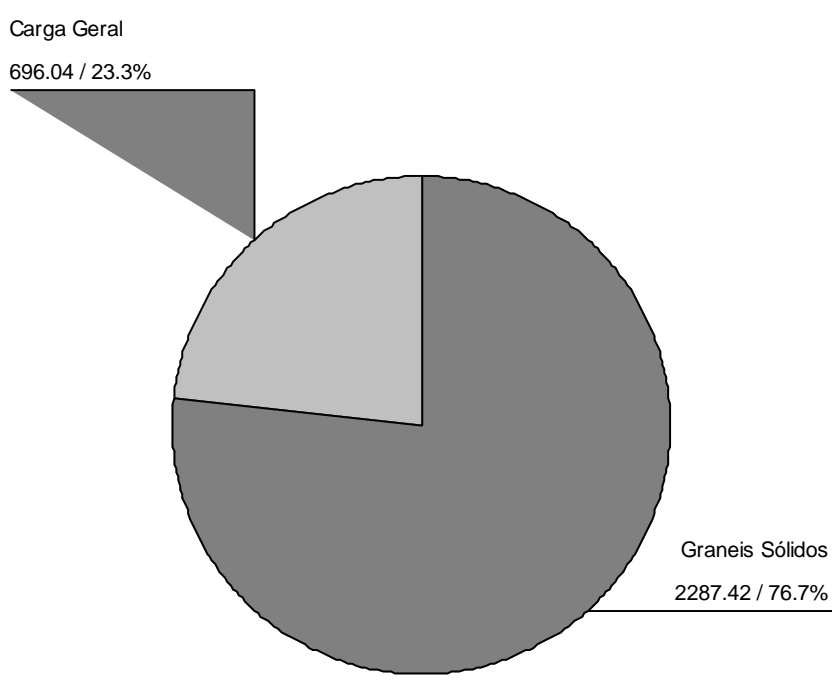

Figura 2. Movimentação na hidrovia Paraná em 2009 (em TKU e Percentual).

De acordo com Caixeta-Filho (2001) o terminal de Presidente Epitácio, por possuir conexão ferroviária, se mostra mais econômico com relação à alternativa rodoviária, no entanto a ferrovia se encontra paralisada.

O Brasil possui em torno de 39 portos e o porto de Presidente Epitácio está entre os mais importantes, porém existe uma baixa movimentação os valores estão apresentados nas tabelas 1 e 2 . 
Tabela 1. Valores das movimentações de cargas gerais no Porto de Presidente Epitácio no período de 1995 a 2000 e 2008 (AHRANA, 2009).

\begin{tabular}{cccccccc}
\hline \multicolumn{7}{c}{ Movimentação no Porto de Presidente Epitácio } \\
\hline Carga & $\mathbf{1 9 9 5}$ & $\mathbf{1 9 9 6}$ & $\mathbf{1 9 9 7}$ & $\mathbf{1 9 9 8}$ & $\mathbf{1 9 9 9}$ & $\mathbf{2 0 0 0}$ & $\mathbf{2 0 0 8}$ \\
\hline Graneis Geral & 56.306 & 101.518 & 135.997 & 89.780 & 30.495 & 91.037 & 9.000 \\
\hline
\end{tabular}

Tabela 2. Valores das movimentações de cargas mensais no Porto de Presidente Epitácio no período de 1994 a 2000 (AHRANA, 2009).

\begin{tabular}{lrrrrrrr}
\hline \multicolumn{1}{c}{ Mês } & \multicolumn{1}{c}{$\mathbf{1 9 9 4}$} & \multicolumn{1}{c}{$\mathbf{1 9 9 5}$} & \multicolumn{1}{c}{$\mathbf{1 9 9 6}$} & $\mathbf{1 9 9 7}$ & $\mathbf{1 9 9 8}$ & $\mathbf{1 9 9 9}$ & $\mathbf{2 0 0 0}$ \\
\hline Janeiro & 11.570 & 14.882 & 12.197 & 29.508 & 11.097 & - & - \\
\hline Fevereiro & - & 4.862 & 9.380 & 8.115 & 8.820 & - & - \\
\hline Março & 9.521 & - & 12.236 & - & 15.630 & - & 2.611 \\
\hline Abril & 20.423 & 4.944 & - & 2.534 & 12.938 & - & - \\
\hline Maio & 3.418 & 9.800 & - & - & 6.840 & - & 88.426 \\
\hline Junho & 5.610 & 6.943 & - & 13.084 & 7.244 & 14.202 & - \\
\hline Julho & 7.911 & - & - & - & 8.803 & - & - \\
\hline Agosto & 21.584 & - & 10.819 & 25.839 & 15.943 & 14.191 & - \\
\hline Setembro & 14.759 & - & 19.103 & 4.079 & 2.414 & 1.451 & - \\
\hline Outubro & 9.325 & - & 2.635 & 6.600 & 41 & 364 & - \\
\hline Novembro & 5.446 & - & 14.715 & 19.039 & - & 287 & - \\
\hline Dezembro & - & 14.875 & 20.433 & 27.199 & - & - & - \\
\hline Total & $\mathbf{1 0 9 . 5 6 7}$ & $\mathbf{5 6 . 3 0 6}$ & $\mathbf{1 0 1 . 5 1 8}$ & $\mathbf{1 3 5 . 9 9 7}$ & $\mathbf{8 9 . 7 7 0}$ & $\mathbf{3 0 . 4 9 5}$ & $\mathbf{9 1 . 0 3 7}$ \\
\hline
\end{tabular}

Foi realizada uma análise descritiva dos

a Figura 3.

dados por meio de técnicas estatísticas da

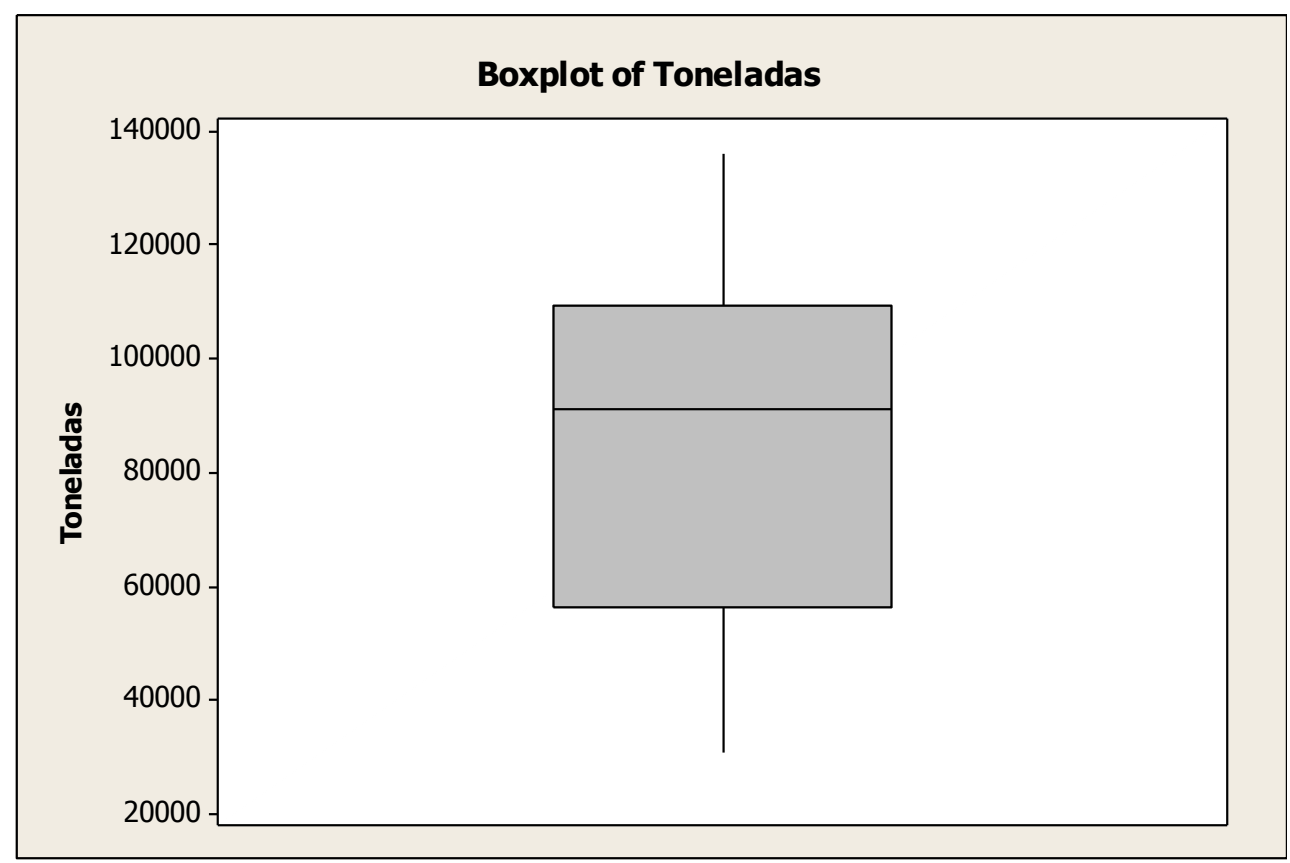

Figura 3. Boxplot do valor de carga anual do Porto de Presidente Epitácio. 
Analisando a Figura 3, é possível verificar que a mediana dos dados está próxima de $90 \mathrm{mil}$ toneladas de carga geral e que existe uma grande variação nas quantidades de cargas de 1994 a 2008. Pela tabela 1 verifica que em 2008 houve grande defasagem na quantidade de cargas 0 porto movimentou apenas 9.000 toneladas, acredita-se que este fato ocorreu pelas facilidades e o aumento do modal rodoviário, e a ferrovia se encontrar paralisada. Entre 1994 e 2000 houve constante movimentação no porto em relação à quantidade de carga anual.
A Figura 4 configura a movimentação de carga anual no porto de Epitácio, nota-se que em 2000 houve movimentação extremamente alta em alguns meses comparando com anos anteriores, porém esta movimentação não foi uniforme durante os meses. O Porto de Presidente Epitácio tem condições de receber cargas mensais altas conforme tabela 2. E possui projetos de investimento pré-aprovados, para aumentar a quantidade de movimentação de carga mensal do porto.

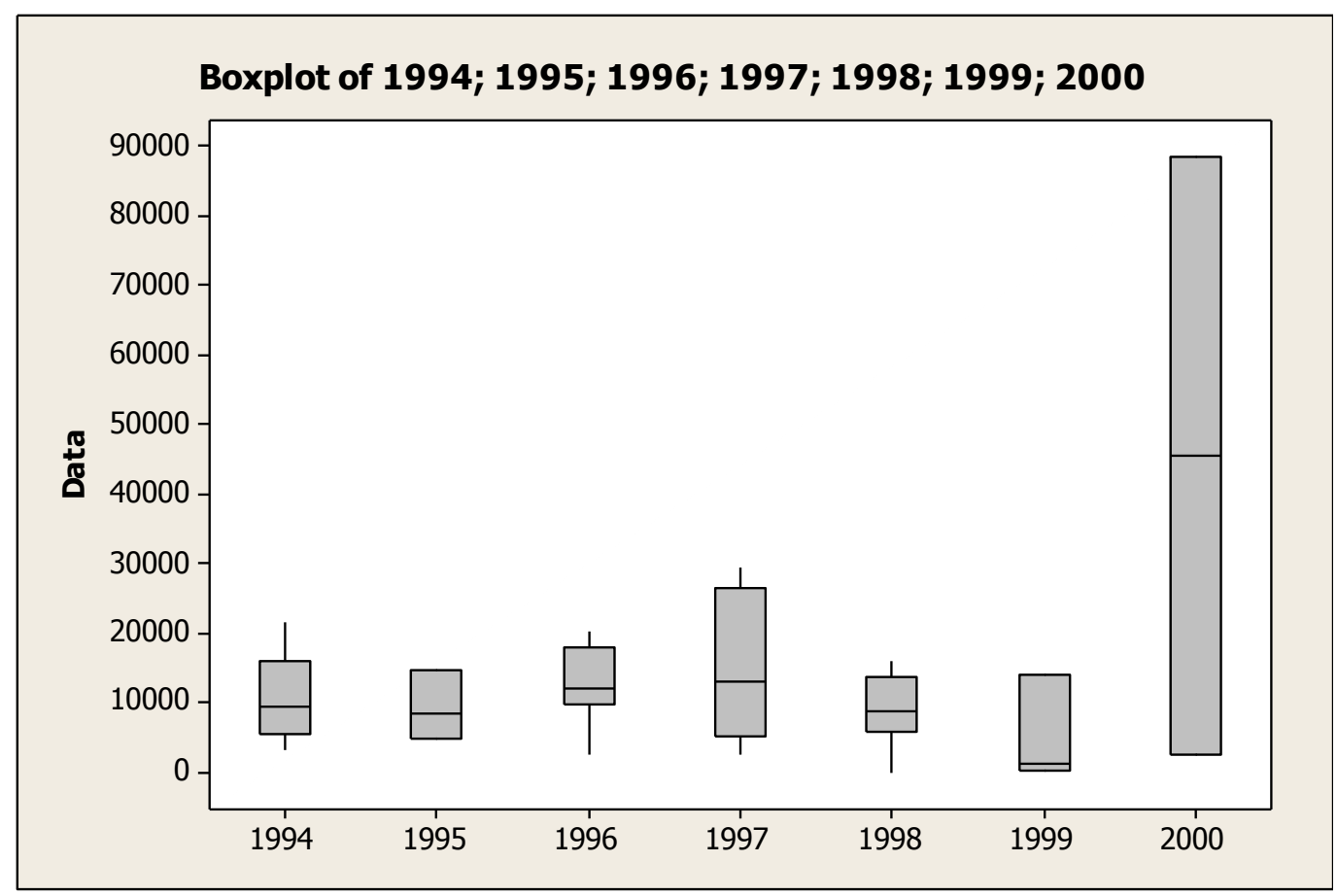

Figura 4. Boxplot do valor de carga mensal nos anos de 1994 a 2000 do Porto de Presidente Epitácio.

A Figura 5 ilustra 0 declínio da movimentação de carga no porto durante os anos. Nota-se a ausência de movimentação durante os anos de 2001 a 2007. No entanto, em 1997 uma carga significativa passou pelo porto, já em 1999 verifica-se que a quantidade em toneladas foi extremamente baixa para a capacidade do Porto. Este fato ocorre devido o aumento de movimentação com modal rodoviário que apesar de maior custo oferece maior flexibilidade. 


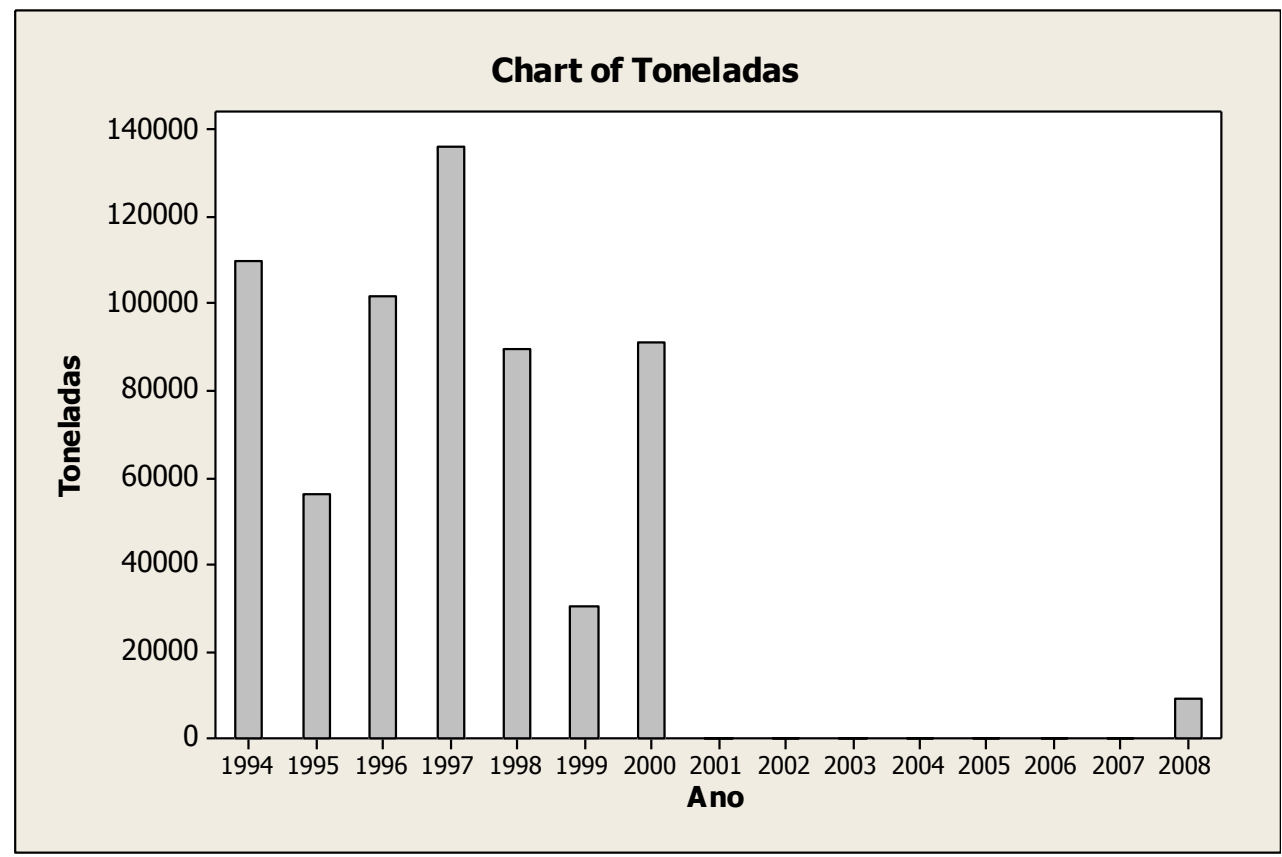

Figura 5. Gráfico de barras dos dados da movimentação do porto.

\section{Conclusões}

Constata-se que o terminal de Presidente Epitácio tem condições plenas de atender 0 escoamento de cargas agrícolas nacionais, assim como do Mercosul. A infra-estrutura não esta concluída mais se encontra em ótimo estado. Pode se verificar que um dos motivos da sua baixa participação no transporte nacional ocorre pela preferência do modal rodoviário e pelo fato da ferrovia estar paralisada, mas que provavelmente ainda neste ano será reativada. Há tendência de crescimento e investimentos no porto para os próximos anos.

Já a baixa participação do porto no mercado internacional do Mercosul ocorre pelo fato do desconhecimento da via.

\section{Referências}

Administração da Hidrovia Paraná (AHRANA). Disponível em: <http://www.transportes.gov.br/Modal/Portuario/E statistica/anuario2000/PresidenteEpitacio.htm>. Acesso: abril de 2009

Administração do Terminal Portuário de Presidente Epitácio (ATEPPE). Disponível em: < http://www.ateppe.com.br/ >. Acesso: maio de 2009
Atlas do Transporte: Confederação Nacional de Transporte. Brasília: CNT, 2006.

BARAT, J. (Org.). Logística e transporte no processo de globalização: oportunidades para o Brasil. São Paulo: UNESP: IEEI, 2007.

BRAVIN, L. F. N. Análise de transporte Multimodal na região da Hidrovia TietêParaná, 2001. Dissertação de Mestrado em Agronomia/Energia na Agricultura apresentada à Faculdade de Ciências Agronômicas da Universidade Estadual Paulista.

CAIXETA-FILHO, J.V; GAMEIRO, A.H. (Orgs.). Sistemas de gerenciamento de transporte: modelagem matemática. São Paulo: Atlas, 2001.

Confederação Nacional do Transporte (CNT). Disponível em: $<$ http://www.sistemacnt.org.br/portal/webCanalNot iciasCNT/noticia. aspx?id=9cdc9dff-bcad-40b2b2e6-18bf5e391e46>. Acesso: setembro de 2009.

FELIPE JUNIOR, N. F. A hidrovia TietêParaná e a intermodalidade no estado São Paulo, 2008. Dissertação de Mestrado em Geografia apresentada à Faculdade de Ciências e Tecnologia da Universidade Estadual Paulista. 